\title{
García Pascual, Cristina, Ansuátegui Roig, Francisco Javier y Bilotti, Domenico. La regola del mondo. La controversia sul diritto internazionale. Edizioni Scientifiche Italiane, Nápoles, 2018, 86 pp.
}

\author{
Jose Antonio García Sáez \\ Instituto de Derechos Humanos \\ Departamento de Filosofía del Derecho y Política \\ Universitat de València
}

Fecha de recepción 01/12/2019 I De publicación: 27/12/2019

Este libro es el resultado de un seminario organizado en el marco del doctorado de investigación en Teoría del derecho y orden jurídico y económico europeo de la Universidad Magna Graecia di Catanzaro. El mencionado seminario, que tuvo lugar en el mes de junio de 2016, giró en torno a la obra de la profesora Cristina García Pascual Norma mundi. La lucha por el derecho internacional (Trotta, 2015). Como ya he podido expresar en la recensión que dediqué a aquella obra ${ }^{1}$, Norma mundi, es un libro único en su especie. Un libro que emprende la tarea de realizar un recorrido iusfilosófico por el derecho internacional, que tiende puentes entre las disciplinas de la filosofía del derecho y del derecho internacional, y que permite sentar las bases para un diálogo constructivo entre sus especialistas.

Es precisamente un fragmento de ese diálogo del que podemos disfrutar leyendo las páginas de los tres ensayos que componen el breve volumen La regola del mondo. La apertura corre a cargo de la propia Cristina García Pascual, que expone algunas de las ideas principales aparecidas en Norma mundi, en particular la referente a la cuestión existencial de la naturaleza del derecho internacional ${ }^{2}$. A continuación, Francisco Javier Ansuátegui toma el texto de García Pascual para realizar algunas reflexiones sobre la filosofía del derecho internacional, un campo de investigación que él considera que conduce tanto hacia el escepticismo como hacia la esperanza ${ }^{3}$. Por último, Domenico Bilotti cierra el libro con un ensayo da cuenta de la compleja cuestión de los fundamentos éticos y religiosos del derecho internacional. Veamos con algo de detenimiento cada uno de los textos.

\footnotetext{
${ }^{1}$ En Anuario de Filosofía del Derecho, tomo XXXII, 2016, pp. 550-553.

${ }^{2}$ La traducción italiana de este capítulo corre a cargo de Laura Volpe. Puede encontrarse la versión original en lengua española, "La naturaleza del derecho internacional. Una cuestión existencial”, en Anuario de Filosofía del derecho, tomo XXIV, 2018, pp. 149-176.

${ }^{3}$ La traducción italiana de este capítulo corre a cargo de Michele Zezza. Puede encontrarse la versión original en lengua española, "Filosofía del derecho internacional: escepticismos y esperanzas", en Materiales de Filosofia del Derecho, No 2017/03, Universidad Carlos III de Madrid.
} 
García Pascual toma como punto de inicio la invitación formulada por Dworkin en uno de sus últimos escritos a «nutrir las raíces del derecho internacional»; esto es, a tomar en serio el problema de la naturaleza de este orden jurídico. Esa cuestión existencial, la de dar una cumplida respuesta a la legítima duda sobre qué sea el derecho internacional, un día ocupó a los internacionalistas, era abordada en los manuales de la disciplina y era discutida en las facultades de derecho. Hoy, sin embargo, vivimos en un tiempo en el que el derecho internacional viene marcado por la fragmentación que tan profusamente ha señalado Koskenniemi. El espacio internacional parece estar dividido en una pluralidad de ordenamientos - el derecho de los derechos humanos, el derecho comercial, el derecho medioambiental, etc. - que actúan de forma poco coordinada, cuando no totalmente inconexa. La idea del derecho internacional como un sistema $\mathrm{y}$, por lo tanto, como un ordenamiento completo $\mathrm{y}$ coherente, a la manera en que lo pensó Kelsen, parece haber quedado lejos de la práctica contemporánea de los juristas internacionalistas. Ante este panorama, García Pascual toma el guante lanzado por Dworkin y se dedica a repensar la cuestión existencial del derecho internacional. Hacerlo no es un mero pasatiempo, sino una necesidad teórica importante en un tiempo saturado de escepticismo y necesitado de claridad conceptual. En un tiempo en el que no debemos olvidar que la aplicación y la interpretación de las normas depende fuertemente de las premisas morales y políticas que adoptemos. No hacer frente a esas premisas, obviarlas como si no existieran, vuelve errática y desencaminada la práctica del jurista. Por esa razón, resurge el impulso de elaborar una filosofía del derecho internacional que pueda abordar con profundidad y coherencia las preguntas derivadas de la cuestión existencial del derecho internacional.

Siguiendo ese hilo, García Pascual se encarga de destacar la manera en la que los filósofos del derecho han tratado el orden internacional. A menudo lo han hecho considerándolo una «cláusula de cierre» de sus propias teorías. Si vemos libros fundamentales como la Teoría pura del derecho de Kelsen o El concepto de derecho de Hart, comprobaremos como el último capítulo está dedicado a la cuestión del derecho internacional. Si atendemos a las carreras de grandes filósofos del derecho, podremos comprobar que el derecho internacional forma parte de las preocupaciones de su madurez, como si no quisieran concluir sus obras sin intentar darles una dimensión global. Es el caso de Rawls o Dworkin, por citar solamente algunos de los contemporáneos. Otros, como Kelsen, Schmitt, Habermas o Bobbio, han integrado el derecho internacional en el conjunto de sus obras, y sus teorías no podrían ser cabalmente entendidas si prescindiéramos del elemento internacionalista. 
El terreno del derecho internacional no es, sin embargo, un terreno fácil, como se encarga de mostrar García Pascual. Es un ámbito fuertemente condicionado por el poder que emana de la soberanía de los estados, por la política en todas sus dimensiones. Una respuesta pulcramente técnica del jurista resultará con frecuencia insuficiente para resolver un conflicto internacional. El derecho se muestra en este espacio como algo sucio, contaminado, embarrado por una multitud de condicionantes ajenos a la lógica de razón y universalidad que caracteriza a lo jurídico. De nuevo, Koskenniemi ha proporcionado los términos con los que entender las aguas en las que navega el internacionalista: entre la apología y la utopía. ¿De qué manera, y con qué herramientas, abordar las contradicciones que plantea esta tensión? Esa es, con toda seguridad, una pregunta que hay que contribuir a resolver desde la filosofía del derecho. Y de ese ejercicio no se beneficiarán únicamente quienes se dedican a la práctica del derecho internacional, sino también la propia teoría del derecho, que encuentra en el orden internacional su más duro «banco de pruebas».

Hans Kelsen es el principal autor en el que García Pascual se apoya para abordar la cuestión existencial del derecho internacional. En efecto, Kelsen ha sido con toda seguridad el teórico del derecho que se preocupó con mayor consistencia, profundidad y extensión por el orden internacional. La teoría kelseniana representa exactamente lo contrario de la contemporánea imagen de la fragmentación. Para Kelsen, el principio de unidad propio del derecho impone una solución monista que lleva a considerar que el ordenamiento internacional y los ordenamientos estatales no pueden ser vistos como realidades diferentes e inconexas; sino que debe existir entre ellos una relación sistemática determinada por su unidad lógica. Se trata de llevar el postulado de la universalidad del derecho hasta sus últimas consecuencias. Ahora bien, precisamente la estricta metodología de la teoría pura kelseniana, es la que impide considerar que, dentro de esa unidad, sea el derecho internacional el que se encuentre necesariamente en un plano de superioridad respecto del derecho estatal. Esa cuestión, dirá Kelsen, es una cuestión relativa a las preferencias morales y políticas y que, por lo tanto, no podría ser resuelta por el jurista actuando como jurista. Este es quizá el principal punto débil de su teoría internacionalista, pero también supone la paradójica confirmación de que el jurista que opera en el ámbito internacional no puede ser un iluso. Debe ser consciente de los condicionamientos de su trabajo precisamente para poder reivindicar la importancia del derecho.

En el segundo de los ensayos, Francisco Javier Ansuátegui realiza una serie de precisiones conceptuales que servirán a quien quiera iniciarse en el ámbito de la filosofía del derecho internacional. 
Partiendo de la constatación de que «la reflexión sobre lo jurídico no debe circunscribirse al ámbito estatal», Ansuátegui ve en el ámbito internacional un escenario óptimo para pensar las siempre inevitables tensiones entre el derecho y la política. En concreto, centra su reflexiones en tres asuntos particularmente trascendentes: 1) la existencia del derecho internacional, 2) el papel insoslayable del estado en el derecho internacional, y 3) la materialización del derecho internacional y sus desafíos. Respecto de la primera cuestión, se hace un repaso por las distintas formas de justificar la necesidad del derecho — pensadas tradicionalmente respecto del derecho estatal—y su posible aplicación al ámbito internacional. Ansuátegui se cuestiona si es necesaria una específica teoría del derecho internacional; o si bien el marco de la teoría general del derecho resulta ya suficiente para dar respuesta a las particularidades del orden internacional. Respecto de la segunda cuestión, se recuerda la distinción entre la dimensión autoritativa y la dimensión justificativa del derecho. Ambas dimensiones sirven para analizar el grado de legitimidad de una norma jurídica y esa resulta justamente una de las encrucijadas a las que se enfrenta el derecho internacional: por un lado, aunque se pueda dar por superado el paradigma westfaliano, la intermediación de los estados parece seguir siendo necesaria para garantizar la efectividad de los derechos humanos; por otro lado, la soberanía de los estados continua irguiéndose como la principal traba al progreso técnico del derecho internacional. Respecto de la tercera cuestión, Ansuátegui muestra su preocupación por el contenido del derecho internacional, donde los derechos no encuentran a su juicio la centralidad normativa de la que gozan en el derecho estatal. Presenta, pues, la democracia y los derechos como dos ingredientes de los que ciertamente no se puede prescindir en el desarrollo de ese ideal que es la norma mundi.

Domenico Bilotti, por su parte, aporta profundidad sobre la dimensión ética y religiosa del derecho internacional. Resulta sabido que la propia fundación del derecho internacional moderno, que suele situarse en la Paz de Westfalia, sirve para poner fin a las seculares guerras religiosas que se sucedían en el continente europeo. El orden westfaliano permite un cierto pluralismo religioso guiado por el principio cuius regio, eius religio, al tiempo que formaliza las reglas que hacen posible la relación entre los nuevos estados soberanos, incluyendo entre esas reglas las que regulan la guerra como un instrumento más de la política internacional. La obra de Grocio De Iure Belli Ac Pacis supone seguramente el mejor exponente del paradigma westfaliano del derecho internacional y refleja, al mismo tiempo, una visión iusnaturalista profundamente influenciada por la fe religiosa del autor holandés. Acierta Bilotti en comparar la teoría grociana con la kelseniana. Aunque ambas representan 
paradigmas del derecho internacional completamente distintos, pueden encontrarse interesantes paralelismos en el afán de ambos autores por encontrar una auténtica norma fundamental del orden internacional, o la justificación de ese elemento aparentemente inevitable del derecho internacional que es la guerra.

En definitiva, este pequeño libro supone una contribución más al creciente número de obras que abordan los problemas del derecho internacional desde una óptica iusfilosófica. Es deseable que el camino iniciado por la profesora Cristina García Pascual siga produciendo más debates que contribuyan a desenmarañar esa madeja de enredos conceptuales que existen en torno al derecho internacional, transformado en ocasiones en un «derecho global». 